\title{
CAMA
}

Centre for Applied Macroeconomic Analysis

\section{Uncertainty and monetary policy in good and bad times: A Replication of the VAR investigation by Bloom (2009)}

\section{CAMA Working Paper 74/2020 August 2020}

\section{Giovanni Caggiano}

Monash University

University of Padova

Bank of Finland

Centre for Applied Macroeconomic Analysis, ANU

\section{Efrem Castelnuovo}

University of Melbourne

University of Padova

Centre for Applied Macroeconomic Analysis, ANU

\section{Gabriela Nodari}

Reserve Bank of Australia

\section{Abstract}

This paper revisits the well-known VAR evidence on the real effects of uncertainty shocks by Bloom (Econometrica 2009(3): 623-685. doi: 10.3982/ECTA6248). We replicate the results in a narrow sense using Eviews. In a wide sense, we extend his study by working with a smooth transition-VAR framework that allows for business cycle-dependent macroeconomic responses to an uncertainty shock. We find a significantly stronger response of real activity in recessions. Counterfactual simulations point to a greater effectiveness of systematic monetary policy in stabilizing real activity in expansions. 


\section{Keywords}

Uncertainty shocks, nonlinear Smooth Transition Vector AutoRegressions, Generalized Impulse Response Functions, systematic monetary policy

\section{JEL Classification}

C32, E32

\section{Address for correspondence:}

(E) cama.admin@anu.edu.au

\section{ISSN 2206-0332}

The Centre for Applied Macroeconomic Analysis in the Crawford School of Public Policy has been established to build strong links between professional macroeconomists. It provides a forum for quality macroeconomic research and discussion of policy issues between academia, government and the private sector.

The Crawford School of Public Policy is the Australian National University's public policy school, serving and influencing Australia, Asia and the Pacific through advanced policy research, graduate and executive education, and policy impact. 


\title{
Uncertainty and monetary policy in good and bad times: A Replication of the VAR investigation by Bloom (2009)*
}

\author{
Giovanni Caggiano \\ Monash University \\ University of Padova \\ Bank of Finland \\ Centre for Applied Macroeconomic Analysis \\ Efrem Castelnuovo \\ University of Melbourne \\ University of Padova \\ Centre for Applied Macroeconomic Analysis \\ Gabriela Nodari \\ Reserve Bank of Australia
}

June 2020

\begin{abstract}
This paper revisits the well-known VAR evidence on the real effects of uncertainty shocks by Bloom (Econometrica 2009(3): 623-685. doi: 10.3982/ECTA6248). We replicate the results in a narrow sense using Eviews. In a wide sense, we extend his study by working with a smooth transition-VAR framework that allows for business cycle-dependent macroeconomic responses to an uncertainty shock. We find a significantly stronger response of real activity in recessions. Counterfactual simulations point to a greater effectiveness of systematic monetary policy in stabilizing real activity in expansions.
\end{abstract}

*We thank Barbara Rossi (the Editor) and two anonymous referees for valuable comments. The opinions expressed in this paper are those of the authors and do not necessarily reflect those of the Bank of Finland or the Reserve Bank of Australia. Financial support from the Australian Research Council via the Discovery Grants DP160102281 and DP190102802 is gratefully acknowledged. Corresponding author: Efrem Castelnuovo, efrem.castelnuovo@gmail.com . 
Keywords: Uncertainty shocks, nonlinear Smooth Transition Vector AutoRegressions, Generalized Impulse Response Functions, systematic monetary policy.

JEL codes: C32, E32. 


\section{Introduction}

This paper replicates, as well as extends, the VAR analysis conducted by Bloom (2009) on the real effects of uncertainty shocks. ${ }^{1}$ Bloom provides codes in Stata and $\mathrm{R}$ to produce his VAR results. To replicate them in a narrow sense, we used Eviews. Our narrow replication also covers robustness checks dealing with filtered and unfiltered financial volatility as proxies for uncertainty. We then extended, in a wide sense, Bloom's work to allow for nonlinear real effects of uncertainty shocks. We did so by estimating a Smooth Transition-VAR model via the Markov-Chain Monte Carlo simulation method proposed by Chernozhukov and Hong (2003). We employed the Matlab code set up by Auerbach and Gorodnichenko (2012), which we extended to allow for fully nonlinear impulse response functions.

A nonlinear replication of Bloom's (2009) findings is interesting in light of the recent COVID-19 outbreak. The COVID-19 shock has taken the world by storm, and some indicators of uncertainty - in particular, financial uncertainty - have recorded heights comparable to those realized in 1987 and 2008. More than ever, it is therefore crucial to rely on solid empirical facts to understand the real effects of uncertainty shocks. Bloom (2009) proposes a partial equilibrium model featuring nonconvex adjustment costs on the labor and capital markets that is able to replicate his VAR facts. Such model represents a key reference for the construction of more complex, general equilibrium frameworks (e.g., Bloom, Floetotto, Jaimovich, Saporta-Eksten, and Terry (2018), Lanteri (2018), Dibiasi (2018)). At the same time, the empirical literature, typically using small-scale VARs, has found that the real effects of uncertainty shocks are particularly acute in recessions (see Caggiano, Castelnuovo, and Groshenny (2014), Nodari (2014), Caggiano, Castelnuovo, and Pellegrino (2017), Caggiano, Castelnuovo, and Figueres (2017), Ferrara and Guérin (2018), and Chatterjee (2019)). Our paper, which deals with Bloom's (2009) medium-scale VAR, shows that Bloom's (2009) results are: i) replicable; ii) robust to working with non-dichotomic uncertainty indicators; ii) robust to working with nonlinear frameworks. This result can easily be interpreted in light of the "wait-and-see" transmission channel studied by Bloom (2009), Bloom, Floetotto, Jaimovich, Saporta-Eksten, and Terry (2018), Lanteri (2018), Dibiasi (2018). Finally, our paper shows that systematic monetary policy is less effective as a stabilization tool during a recession. This last analysis complements the ones on the effects

\footnotetext{
${ }^{1}$ The data used in this study are available at Nicholas Bloom's webpage: https://nbloom.people.stanford.edu/sites/g/files/sbiybj4746/f/replication.zip.
} 
of monetary policy shocks in high/low uncertainty regimes by Pellegrino (2017, 2018) and Castelnuovo and Pellegrino (2018), and those on the "risk-management" approach undertaken by the Federal Reserve when tackling uncertainty shocks (Evans, Fisher, Gourio, and Krane (2015) and Caggiano, Castelnuovo, and Nodari (2018)).

The remainder of the paper is structured as follows. In Section 2, we document the data used in Bloom's study. Section 3 presents details for the replication in a narrow sense. Section 4 extends Bloom's (2009) VAR analysis to allow for nonlinear macroeconomic responses to an uncertainty shock, and it runs a counterfactual analysis to investigate if systematic monetary policy is differently powerful in good and bad times. Section 5 concludes. The working paper version of this paper adds to this analysis by proposing: i) further details and robustness checks related to our nonlinear investigation; ii) a quantification of the monetary policy effectiveness in recessions vs. expansions; iii) a comparison between impulse responses to an uncertainty shock vs. to a first-moment financial shock; iv) a discussion on counterfactual simulations done with VAR frameworks and the Lucas critique. ${ }^{2}$

\section{Data description}

We use the same data and sample investigated by Bloom (2009) to estimate a linear VAR with a constant and 12 lags (as Bloom's). The vector $X_{t}$ of endogenous variables we model features (from the top to the bottom) the S\&P500 stock market index, an uncertainty dummy based on the VXO, the federal funds rate, a measure of average hourly earnings, the consumer price index, hours, employment, and industrial production. We use monthly data covering the period July 1962-June 2008. The realized volatility of the returns of the S\&P500 index is used before 1986 due to the unavailability of the VXO. The uncertainty dummy takes the value of 1 when the HP-detrended VXO level rises over 1.65 standard deviations above the mean, and 0 otherwise. Variables are in logs, except the uncertainty dummy, the policy rate, and hours. ${ }^{3}$

\footnotetext{
${ }^{2}$ The working paper version is available at https://sites.google.com/site/efremcastelnuovo/home/

${ }^{3}$ Following Bloom (2009), we Hodrick-Prescott filter these variables (other than the VXO), with a smoothing weight equal to 129,600 . Bloom (2009) shows that his results are robust to not pre-filtering the variables in his VAR. When turning to our non-linear analysis, we work with non-filtered variables to avoid inducing spurious cyclical fluctuations which could bias our results (Cogley and Nason (1995), Wong and Wiriyawit (2016)).
} 


\section{Replication of Bloom's (2009) results}

Figure 1 - first column plots the impulse responses of industrial production (first row) and employment (second row) to a unit uncertainty shock, along with $68 \%$ analytically computed confidence bands. These responses are exactly the ones documented by Bloom (2009) in his Figures 2 (industrial production) and 3 (employment). Industrial production displays a quick drop of around $1 \%$ within 4 months, with a subsequent recovery and rebound from 7 months after the shock. The drop and rebound pattern is statistically significant. Employment displays a similar pattern. ${ }^{4}$

It is of interest to check the robustness of these findings in light of two issues related to the use of Bloom's (2009) dichotomic (0/1) dummy. The first one is that such dummy is implicitly assumed to be a "normal" endogenous time series in the context of this model. However, this dummy actually reads as a censored time series, and the type of censoring applied here does not seem to match the censoring discussed in, e.g., Mertens and Ravn $(2013,2014)$ (who aim at identifying the business cycle effects of fiscal policy shocks) and also analyzed in Jentsch and Lunsford (2019). Mavroeidis (2020) investigates the properties (existence and uniqueness of an equilibrium) of multiple equation systems (like VARs) in which censored variables are modeled. An application to monetary policy shocks in presence of the zero lower bound shows that, if not properly dealt with, inference in VAR frameworks characterized by censored variables may produce misleading results. The second related issue is that contributions subsequent to Bloom (2009) have chosen to model uncensored and unfiltered proxies for financial uncertainty (see, e.g., Caggiano, Castelnuovo, and Groshenny (2014), Nodari (2014), Leduc and Liu (2016), Basu and Bundick (2017), Ludvigson, Ma, and Ng (2019)). To deal with these issues, we replace the 0/1 dummy with: i) an uncensored and unfiltered measure of financial volatility (the VXO, merged with realized financial volatility before 1986); ii) an uncensored but filtered measure of financial volatility (again, the VXO). We then re-estimate the VAR, and re-compute the responses to an uncertainty shock. The second and third columns of Figure 1 documents the robustness of Bloom's (2009) results to employing these alternative proxies for uncertainty. Finally, Bloom's sample end in June 2008. It is of obvious interest to understand if his results hold to using a longer sample. We then extend the sample to February 2020, and compute the impulse

\footnotetext{
${ }^{4}$ Figures 2 and 3 in Bloom (2009) also display the response of industrial production and employment to a $1 \%$ impulse to the federal funds rate. Given that our focus is on uncertainty shocks, we decided to omit the evidence on the effects of monetary policy shocks. Such evidence (which replicates exactly Bloom's) is available upon request.
} 
responses to an uncertainty shock. Figure 1 - fourth column documents, once again, the solidity of Bloom's (2009) results to employing 12 extra years of data with respect to his original analysis. ${ }^{5}$

\section{Nonlinear analysis}

STVAR framework. The vector of endogenous variables $\boldsymbol{X}_{t}$ is modeled with the following STVAR (for a detailed presentation, see Teräsvirta, Tjøstheim, and Granger, 2010):

$$
\begin{aligned}
\boldsymbol{X}_{t} & =F\left(z_{t-1}\right) \boldsymbol{\Pi}_{R}(L) \boldsymbol{X}_{t}+\left(1-F\left(z_{t-1}\right)\right) \boldsymbol{\Pi}_{E}(L) \boldsymbol{X}_{t}+\boldsymbol{\varepsilon}_{t}, \\
\boldsymbol{\varepsilon}_{t} & \sim N\left(0, \boldsymbol{\Omega}_{t}\right), \\
\boldsymbol{\Omega}_{t} & =F\left(z_{t-1}\right) \boldsymbol{\Omega}_{R}+\left(1-F\left(z_{t-1}\right)\right) \boldsymbol{\Omega}_{E}, \\
F\left(z_{t}\right) & =\exp \left(-\gamma z_{t}\right) /\left(1+\exp \left(-\gamma z_{t}\right)\right), \gamma>0, z_{t} \sim d(0,1) .
\end{aligned}
$$

$F\left(z_{t-1}\right)$ is a logistic transition function that captures the probability of being in a recession, $\gamma$ is the smoothness parameter, $z_{t}$ is a business cycle indicator (whose generic distribution $d$ is not necessarily Gaussian), $\Pi_{R}$ and $\Pi_{E}$ are the VAR coefficients capturing the dynamics of the system in recessions and expansions respectively, $\varepsilon_{t}$ is the vector of reduced-form residuals with zero-mean and time-varying, state-contingent variancecovariance matrix $\Omega_{t}$, and $\boldsymbol{\Omega}_{R}$ and $\boldsymbol{\Omega}_{E}$ are the state-dependent covariance matrices of the reduced-form residuals. ${ }^{6}$ The transition variable $z_{t}$ in eq. (4) is the standardized zero mean-unit standard deviation backward-looking moving average of the yearly growth rate of industrial production. The smoothness parameter $\gamma$ is notoriously difficult to estimate because of well-known identification issues (see the discussion in Teräsvirta,

\footnotetext{
${ }^{5}$ The responses documented in Figure 1 - fourth column are computed by considering the $0 / 1$ approach à la Bloom. In updating his dummy, we followed his approach and assigned a value of 1 in correspondence of realizations of the HP-filtered financial volatilty larger than 1.65 standard deviations. In presence of more multiple consecutive realizations over such threshold, we assigned the value of 1 just to the highest realization of the filtered financial volatility (as in Bloom (2009), baseline case). Finally, the results documented in Figure 1 - last column are robust to replacing the federal funds rate with the shadow rate produced by $\mathrm{Wu}$ and Xia (2016).

${ }^{6}$ Note that these state-contingent covariance matrices capture the different conditional volatility in recessions and expansions. A recent paper by Angelini, Bacchiocchi, Caggiano, and Fanelli (2019) quantifies the economic impact of macroeconomic and financial uncertainty shocks by exploiting the information coming from three different volatility regimes in the post-WWII era (great inflation, great moderation, zero lower bound). Given the different dimension of heteroskedasticity we investigate in our paper, we see our approach as complementary to theirs.
} 
Tjøstheim, and Granger (2010)). We calibrate $\gamma=1.8$ to match the frequency of the U.S. recessions, which amounts to $14 \%$ in our sample. The implied model-probability of being in a recession $F\left(z_{t}\right)$ tracks remarkably well the dating of the NBER recessions. Model (1)-(4) is estimated via the Markov-Chain Monte Carlo simulation method proposed by Chernozhukov and Hong (2003). Statistical support to our nonlinear model (against the alternative of a linear VAR) is offered by the test designed by Teräsvirta and Yang (2014). The estimated model is then employed to compute generalized impulse response functions (GIRFs), which take into account the endogeneity of the transition indicator $z_{t}$. For brevity, information on the match between the recession probability implied by our logistic function and the NBER recessions, the statistical test offering support to our nonlinear framework, and the algorithm we use to compute GIRFs is provided in the working paper version of this document.

Results. Figure 2 plots the estimated nonlinear dynamic responses of industrial production and employment to an uncertainty shock of the same size as Bloom's. These variables react negatively and significantly no matter what phase of the business cycle the economy is in. However, in recessions, the peak short-run response of industrial production is about $-2.5 \%$, while that of employment is about $-1.5 \%$. The same values in expansions read, respectively, $-1.5 \%$ and -0.9 . Hence, we find evidence in favor of an asymmetric response of real activity to uncertainty shocks along the business cycle. Turning to monetary policy, Figure 2 (third and fourth rows) shows the effect of an uncertainty shock on aggregate prices and the federal funds rate. An uncertainty shock triggers a temporary fall in prices, which is statistically significant in recessions only. The federal funds rate falls significantly more in recessions - the peak response is about 2 percentage points, compared to 0.8 percentage points in expansions. In the working paper version of this document, we show that industrial production, employment, and the federal funds rate react significantly more in recessions to uncertainty shocks. ${ }^{7}$

Effectiveness of systematic monetary policy. What would have happened if the Federal Reserve had not reacted to the macroeconomic fluctuations induced by uncertainty shocks? We address this question by running a counterfactual exercise that assumes the central bank to stay still after an uncertainty shock, i.e., we shut down the systematic response of the federal funds rate to movements in the economic system

\footnotetext{
${ }^{7} 68 \%$ confidence bands in our nonlinear exercises are computed via simple bootstrap. Consistently with Bloom's (2009) baseline exercise, we work with his 0/1 dummy. As discussed in the text, the distribution of impulse responses is likely nonstandard in this case. Unfortunately, to our knowledge no theory as been developed yet on how to compute generalized impulse responses in presence of censored variables.
} 
due to uncertainty shocks by zeroing the coefficients of the federal funds rate equation in our VAR. We run this exercise with the aim of identifying the effectiveness of the estimated (factual) systematic monetary policy response by contrasting the factual and the counterfactual scenarios.

Figure 3 contrasts the responses of real activity and prices conditional on the absence of the systematic policy response with the baseline results. Focusing on real activity, the differences between the factual and counterfactual responses point to a dramatically lower monetary policy effectiveness in recessions. The recession is estimated to be almost as severe as the one which occurs when policymakers are allowed to lower the policy rate. A different picture emerges when our counterfactual monetary policy is implemented in good times. When the policy rate is kept fixed, industrial production falls markedly (about $-2.5 \%$ at its peak) and persistently, remaining statistically below zero for a prolonged period of time. The same holds when looking at the response of employment, i.e., the gap between the baseline response and the one associated with our counterfactual exercise is quantitatively substantial. Interestingly, prices display a more persistent departure from their trend in both states. Importantly, the relatively lower effectiveness of systematic monetary policy in recessions can be interpreted in the light of models formalizing the "wait-and-see" behavior by firms which, under uncertainty, optimally cut on their capital and labor demand and wait until uncertainty vanishes before resuming their normal level of production (Bloom (2009), Bloom, Floetotto, Jaimovich, Saporta-Eksten, and Terry (2018)), and of models that allow for statedependent non convex adjustment costs (Lanteri (2018), Dibiasi (2018)).

\section{Conclusions}

A replication exercise of Bloom's (2009) VAR results on the real effects of uncertainty shocks in a narrow sense was performed by using Eviews. We obtained exactly the same results documented in the original paper. We then relaxed the assumption of linearity and verified, with a Smooth Transition-VAR framework, the stronger real effects of uncertainty shocks in recessions. Counterfactual simulations revealed that systematic monetary policy exerts stronger effects on real activity in expansions, which implies that monetary policy has to be aggressive in recession to exert the desired stabilizing effect. These results: i) offer support to models featuring "wait-and-see" effects (e.g., Bloom (2009), Bloom, Floetotto, Jaimovich, Saporta-Eksten, and Terry (2018), Lanteri (2018), Dibiasi (2018)); ii) justify the rapid and massive monetary policy interventions by the 
Federal Reserve in response to the COVID-19 uncertainty shock, which materialized in correspondence of the beginning of a recessionary phase in the US. ${ }^{8}$

\section{References}

Angelini, G., E. Bacchiocchi, G. Caggiano, and L. Fanelli (2019): "Uncertainty Across Volatility Regimes," Journal of Applied Econometrics, 34(3), 437-455.

Auerbach, A., and Y. Gorodnichenko (2012): "Measuring the Output Responses to Fiscal Policy," American Economic Journal: Economic Policy, 4(2), 1-27.

BAsu, S., And B. Bundick (2017): "Uncertainty Shocks in a Model of Effective Demand," Econometrica, 85(3), 937-958.

Bloom, N. (2009): "The Impact of Uncertainty Shocks," Econometrica, 77(3), 623685.

Bloom, N., M. Floetotto, N. Jaimovich, I. Saporta-Eksten, and S. J. Terry (2018): "Really Uncertain Business Cycles," Econometrica, 86(3), 1031-1065.

Caggiano, G., E. Castelnuovo, and J. M. Figueres (2017): "Economic Policy Uncertainty and Unemployment in the United States: A Nonlinear Approach," Economics Letters, 151, 31-34.

Caggiano, G., E. Castelnuovo, and N. Groshenny (2014): "Uncertainty Shocks and Unemployment Dynamics: An Analysis of Post-WWII U.S. Recessions," Journal of Monetary Economics, 67, 78-92.

Caggiano, G., E. Castelnuovo, and G. Nodari (2018): "Risk ManagementDriven Policy Rate Gap," Economics Letters, 171, 235-238.

Caggiano, G., E. Castelnuovo, and G. Pellegrino (2017): "Estimating the Real Effects of Uncertainty Shocks at the Zero Lower Bound," European Economic Review, 100, 257-272.

Castelnuovo, E., and G. Pellegrino (2018): "Uncertainty-dependent Effects of Monetary Policy Shocks: A New Keynesian Interpretation," Journal of Economic Dynamics and Control, 93, 277-296.

Chatterjee, P. (2019): "Asymmetric Impact of Uncertainty in Recessions - Are Emerging Countries More Vulnerable?," Studies in Nonlinear Dynamics and Econometrics, 23(2), 1-27.

Chernozhukov, V., And H. Hong (2003): "An MCMC Approach to Classical Estimation," Journal of Econometrics, 115(2), 293-346.

Cogley, T., And J. NAson (1995): "Effects of the Hodrick-Prescott Filter on Trend and Difference Stationary Time-Series: Implications for Business Cycle Research," Journal of Economic Dynamics and Control, 19, 253-278.

\footnotetext{
${ }^{8}$ The NBER dated February 2020 as the first month of the COVID-19-related recession (see https://www.nber.org/cycles.html). Our logistic function, extended up to 2020, also points to a recession in February 2020, with $F\left(z_{2002 M 2}\right)=0.75$.
} 
DiBIAsi, A. (2018): "Non-linear Effects of Uncertainty," KOF ETH Zurich Swiss Economic Institute, mimeo.

Evans, C., J. D. M. Fisher, F. Gourio, and S. Krane (2015): "Risk Management for Monetary Policy Near the Zero Lower Bound," Brookings Papers on Economic Activity, Spring, 141-196.

Ferrara, L., And P. GuÉRin (2018): "What Are The Macroeconomic Effects of High-Frequency Uncertainty Shocks?," Journal of Applied Econometrics, 33(5), 662679 .

Jentsch, C., and C. K. Lunsford (2019): "Asymptotically Valid Bootstrap Inference for Proxy SVARs," Federal Reserve Bank of Cleveland Working Paper No. $19-08$.

LAnteri, A. (2018): "The Market for Used Capital: Endegenous Irreversibility and Reallocation over the Business Cycle," American Economic Review, 108(9), 23832419 .

Leduc, S., And Z. Liu (2016): "Uncertainty Shocks are Aggregate Demand Shocks," Journal of Monetary Economics, 82, 20-35.

Ludvigson, S. C., S. Ma, And S. NG (2019): "Uncertainty and Business Cycles: Exogenous Impulse or Endogenous Response?," American Economic Journal: Macroeconomics, forthcoming.

Mavroeidis, S. (2020): "Identification at the Zero Lower Bound," available at https://sites.google.com/site/sophoclesmavroeidis/research/working-papers.

Mertens, K., and M. O. Ravn (2013): "The Dynamic Effecs of Personal and Corporate Income Tax Changes in the United States," American Economic Review, 103(4), $1212-1247$.

(2014): "A Reconciliation of SVAR and Narrative Estimates of Tax Multipliers," Journal of Monetary Economics, 68, S1-S19.

Nodari, G. (2014): "Financial Regulation Policy Uncertainty and Credit Spreads in the U.S.," Journal of Macroeconomics, 41, 122-132.

Pellegrino, G. (2017): "Uncertainty and Monetary Policy in the US: A Journey into Non-Linear Territory," available at https://sites.google.com/site/giovannipellegrinopg/home.

(2018): "Uncertainty and the Real Effects of Monetary Policy Shocks in the Euro Area," Economics Letters, 162, 177-181.

Teräsvirta, T., D. Tuøstheim, and C. W. Granger (2010): "Modeling Nonlinear Economic Time Series," Oxford University Press, Oxford.

Teräsvirta, T., And Y. Yang (2014): "Linearity and Misspecification Tests for Vector Smooth Transition Regression Models," CREATES Research Papers 2014-04, School of Economics and Management, University of Aarhus.

Wong, B., And V. Wiriyawit (2016): "Structural VARs, Deterministic and Stochastic Trends: How Much Detrending Matters For Shock Identification," Studies in Nonlinear Dynamics and Econometrics, 20(2), 141-157. 
Wu, J. C., AND F. D. XiA (2016): "Measuring the Macroeconomic Impact of Monetary Policy at the Zero Lower Bound," Journal of Money, Credit, and Banking, 48(2-3), 253-291. 

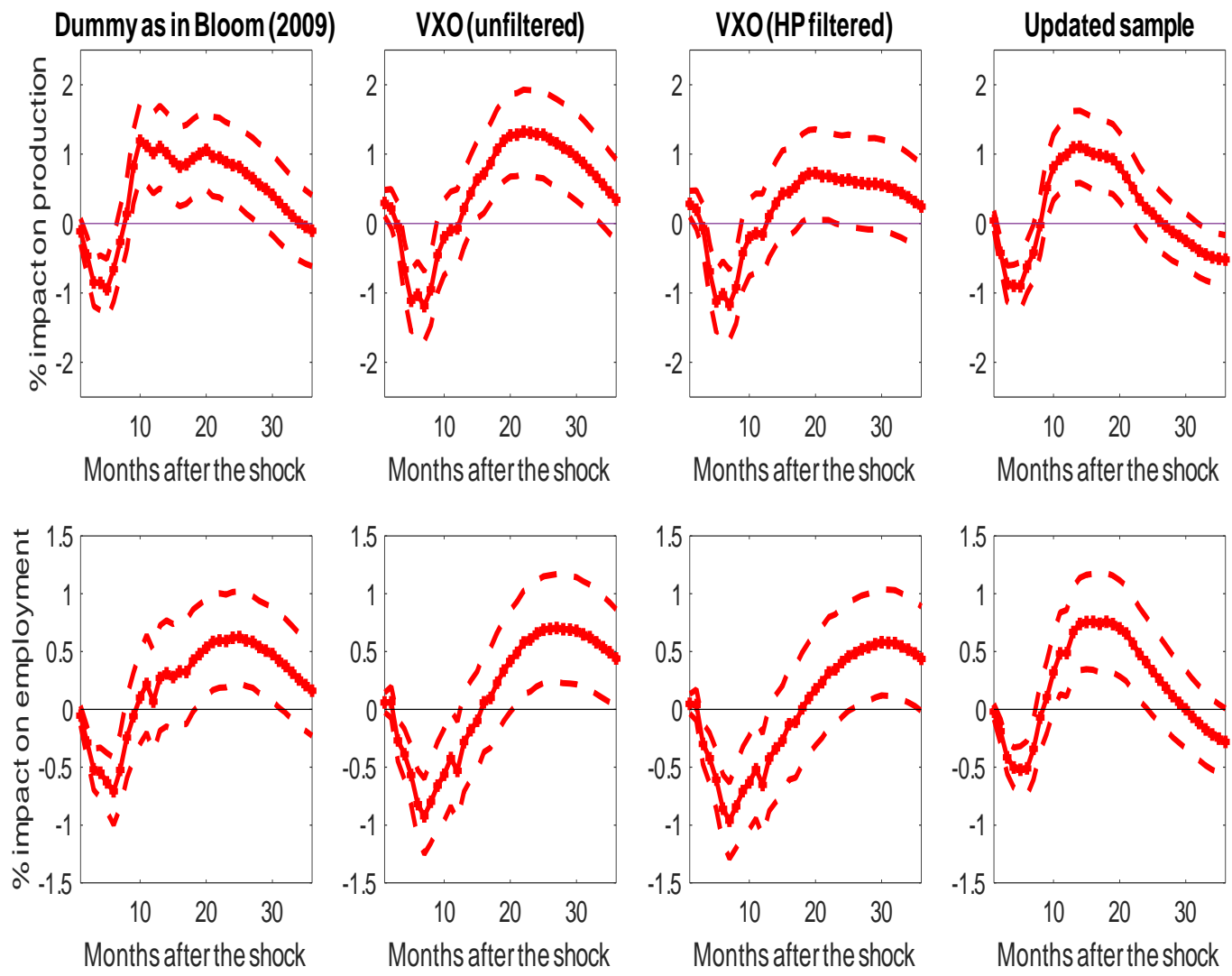

Figure 1: VAR estimation of the impact of an uncertainty shock on industrial production and employment: Replication of Bloom's (2009) evidence and robustness to an alternative proxy for financial uncertainty. Impulse responses (point estimates) to an uncertainty shock inducing an on-impact reaction of uncertainty equal to one as in Bloom (2009). Solid lines with crosses: Point estimates. Dashed lines: $68 \%$ analytical confidence bands. First column: Jumps in financial uncertainty captured by a 0/1 dummy as in Bloom (2009). Second column: Middle panels: Financial uncertainty proxied by financial volatility. Third column: Financial uncertainty proxied by HP-filtered (smoothing parameter: 129,600) financial volatility. Fourth column: Jumps in uncertainty proxied by a $0 / 1$ dummy as in Bloom (2009), sample extended to February 2020. 

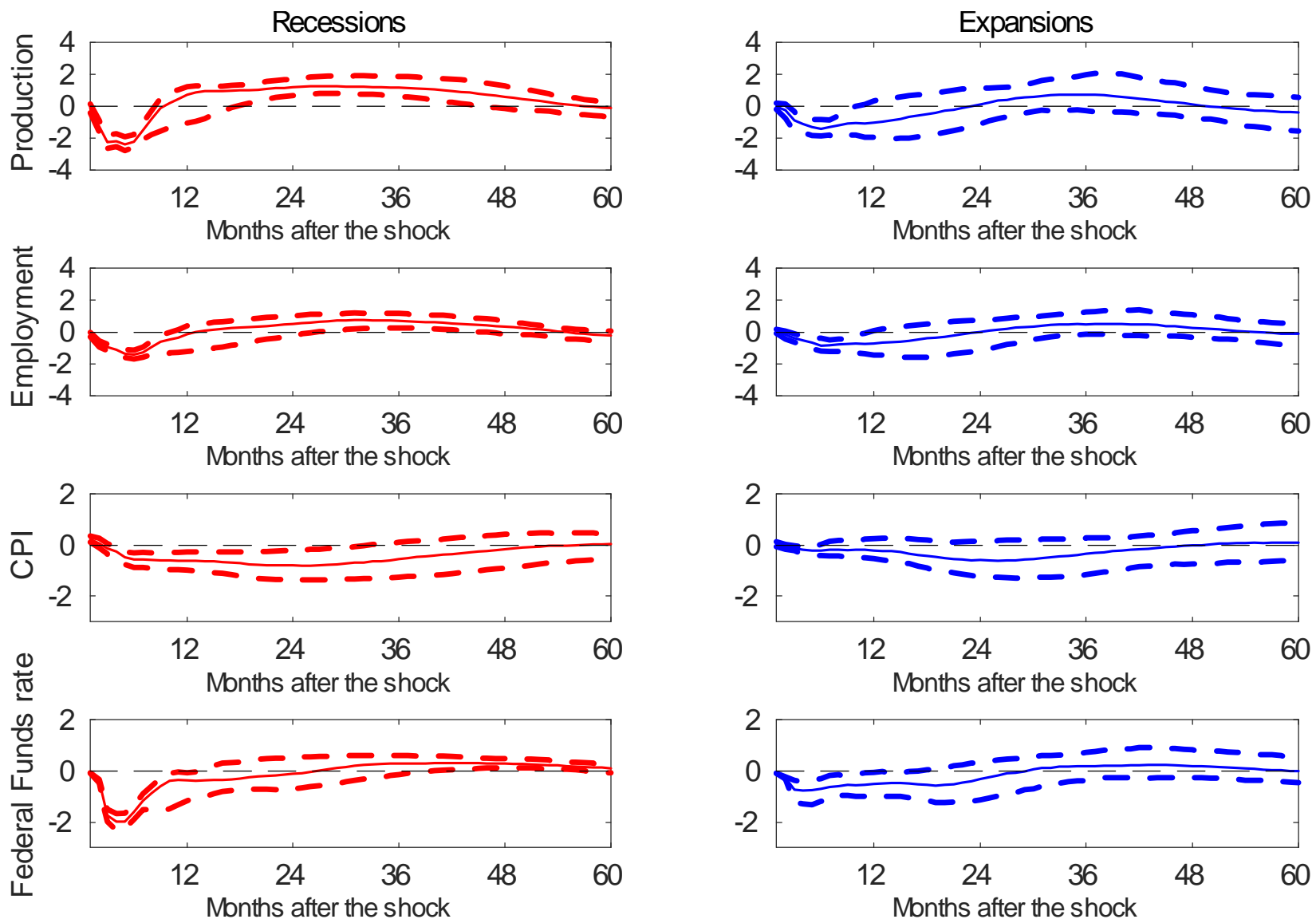

Figure 2: Macroeconomic Effects of Uncertainty Shocks: Good and Bad Times. Impulse responses (median values) to an uncertainty shock inducing an onimpact reaction of uncertainty equal to one as in Bloom (2009). Red (blue) lines: Responses computed with the Smooth-Transition VAR and conditional on recessions (expansions). Dashed lines: 68\% confidence bands. 

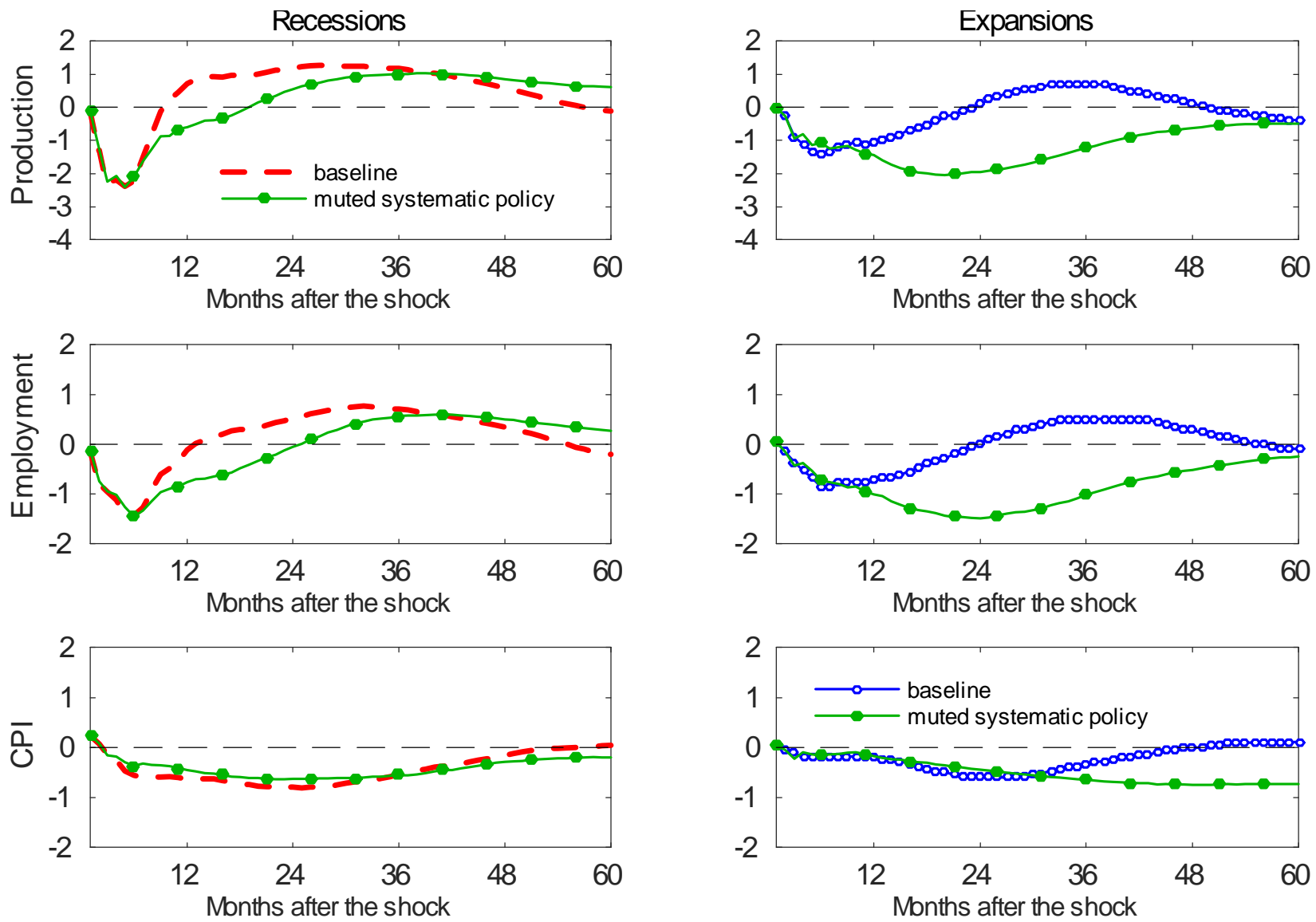

Figure 3: Real Effects of Uncertainty Shocks: Role of Systematic Monetary Policy. Impulse responses (median values) to an uncertainty shock inducing an on-impact reaction of uncertainty equal to one as in Bloom (2009). Responses conditional on unconstrained/constrained monetary policy. Red dashed (blue circled) lines: Responses computed with the Smooth-Transition VAR and conditional on recessions (non-recessionary phases). Counterfactual responses computed conditional on a muted systematic policy (fixed federal funds rate) in green circled lines. 